\title{
Wholly Owned Subsidiary Versus Technology Licensing in the Worldwide Chemical Industry
}

\author{
Ashish Arora* \\ CARNegie Mellon University
}

Andrea Fosfuri**

Univfresidad CARI.OS III DE MadRID

This paper empirically analyzes the determinants of the choice between wholly owned subsidiary and technology licensing as a strategy for expansion abroad. We use a new and comprehensive database on worldwide plant level investments in the chemical industry during the 1981-1991 period. We find that both cultural distance and the presence

\section{INTRODUCTION}

Globalization has underlined the need for firms to exploit technological capabilities on a global scale. Indeed, during the last decades firms have increasingly committed themselves to global markets. This has coincided with a surge in the worldwide flows of foreign direct invest- of other potential licensors favor the use of licensing as a strategy for expanding abroad, whereas, prior experience favors the choice of wholly owned subsidiary. An implication of this study is that competition in the market for technology can foster the international diffusion of technology through the use of arm's length agreements.

ment, which passed $\$ 600$ billion in 1998, a rise in cross-border licensing agreements, and a growth in the number of international alliances (World Investment Report, 1999).

Understanding the factors that condition the choice of the international expansion mode is an important challenge

\footnotetext{
*Ashish Arora is associate professor at the Heinz School of Public Policy and Management, Carnegie Mellon University. His research focuses on the economics of technological change. He has worked extensively on the chemical and software industries.

**Andrea Fosfuri is assistant professor at the Business Department of the University Carlos III, Madrid, and research affiliate at the Centre for Economic Policy Research (CEPR). His research centers on the areas of international economics and business, and technology strategy.

We would like to thank Bruno Cassiman, Javier Cebollada, Fabrizio Cesaroni, Julio de Castro, Alfonso Gambardella, Jaeyong Song, and three anonymous reviewers for their constructive suggestions. Financial support from the European Union through the TSER project No. SOE1CT97-1059 is gratefully acknowledged.
} 
in the field of international business, and a critical determinant of the likely success of the foreign project. We follow in this tradition and focus specifically on whether technological competencies are exploited in foreign markets through licensing agreements or wholly owned subsidiaries. These two alternatives lie at the extremes of a continuum of governance structures ranging from a hierarchy to a market mechanism (Williamson, 1991).

Despite the considerable body of theoretical work (see literature review in the next section), there are relatively few empirical studies that address this topic in a comprehensive way. (Contractor and Kundu, 1998, is a recent exception.) This is mainly due to the difficulty in collecting data that are appropriate to test the hypotheses. Our research uses data on investment projects in the chemical industry worldwide. This is a new and rich database that has not been explored in previous studies of entry mode choice. Although limited to one sector, it has the virtue of being comprehensive, covering the universe of projects undertaken all over the world for a large number of years. This allows us both to control extensively for many sources of heterogeneity in the data and to make a more robust test of some of the determinants of the entry mode choice. In addition, the chemical industry constitutes a natural test-bed for analyzing these issues because it is both a technology-based industry and a global industry.

This paper attempts to shed light on some outstanding questions in this area of research. Specifically: (1) Does cultural distance influence the choice between wholly owned subsidiary and technology licensing? (2) Do firms learn from previous business practices in foreign countries? And, which entry mode does provide more experiential learning to the investor? (3) How does the presence of other potential licensors influence the entry mode choice? The first two issues have been analyzed extensively by scholars in the field of international business. However, as we shall discuss later, the empirical findings are mixed and have not provided a clear-cut answer. The role of the distribution of technological competencies has received very little attention. Yet, the strategic imperatives conditioning the choice between wholly owned subsidiary and licensing depend on whether or not the firm possesses unique and "difficult to replicate" technological capabilities. Our paper offers new and interesting insights about the relationship between competition in technology and entry mode choice.

\section{BACKGROUND}

Forty years ago, Hymer (1960) raised the question of why multinational firms existed at all given the presumed penalties for operating across national and cultural boundaries. The logic put forward by Hymer still remains persuasive: The multinational must bring some inherent advantages that potentially constitute an important edge over local competitors. The principal belief of the theory of foreign direct investment is that the primary advantage that a firm brings to foreign markets is its possession of superior knowledge about technology, production, marketing or other activities.

Although "locational" considerations, such as tariffs, transport costs or comparative advantages, could mandate that the firm not concentrate all operations in one country and export to others (Root, 1987), it still remained to explain why foreign direct investment should be pre- 
ferred to the arm's length use of markets. The "eclectic theory" (Dunning, 1981) pointed to "internalization" advantages. Applying the insights of the transaction cost theory (Williamson, 1991), this approach suggests that, absent significant contracting hazards, the 'default' lowcost governance mechanism is a simple contract. However, writing and executing a reliable contract for the use of technology requires adequate specification of property rights, monitoring and enforcement of contractual terms - any of which may be problematic (Contractor, 1981; Teece, 1988).

An interesting twist to this approach is provided by Kogut and Zander (1993). They argue that "multinational corporations arise not out of the failure of markets for buying and selling knowledge, but out of its superior efficiency as an organizational vehicle by which to transfer this knowledge across borders." Although theoretically different, their approach leads to conclusions and implications that are empirically equivalent to the ones generated by the transaction cost theory. Indeed, they posit that the nature of the knowledge, or technology, is the main determinant of the choice of the mode of international expansion. If the knowledge is tacit, complex and difficult to teach then - they argue - intrafirm transfers of knowledge are easier than inter-firm transfers. However, it is exactly when knowledge is tacit and complex that contracting upon it becomes more problematic and transaction costs are the largest (Teece, 1977; Balakrishnan and Koza, 1993; von Hippel, 1994).

Another important contribution comes from the behavioral theory of the firm, which adds a dynamic component to the earlier picture. The underlying assumption is that firms stay close to their past practices and routines (Cyert and March, 1963) and therefore the process of internationalization can only be gradual and sequential (Johanson and Vahlne, 1977). Firms operating internationally face large uncertainty, to which they respond with a sequential strategy. The so-called U-model (Uppsala) of internationalization of the firm maintains that in this slow process of sequential steps the firm oriented towards globalization learns habits, preferences, and the market structure of the target countries (Johanson and Vahlne, 1977). This experiential knowledge is a critical resource since it is country-specific and it cannot be easily transferred between firms or business units.

The U-model emphasizes two aspects. First, that firms move to distant countries only after having established a presence in more proximate countries. Indeed, the firm's experiential knowledge derived from the domestic market is of limited value in markets located at a great psychic distance (Davidson, 1983; Kogut and Singh, 1988). Therefore, the psychic distance between the home and foreign markets affects market selection as well as the choice of the entry mode. Second, the U-model predicts a sequential increase of commitments through different stages (establishment chain) as long as the firm learns about the foreign market. This process goes through exports first, then the establishment of a marketing subsidiary and concludes with the creation of overseas production facilities (Benito and Grisprud, 1992; Eriksson et al., 1997).

Finally, a more recent approach is provided by the "syncretic" theory of the entry mode choice. This approach, developed by Hill, Hwang and Kim (1990) and Contractor (1990), focuses on the different level of control, resource com- 
mitment and dissemination risk involved respectively in licensing and wholly owned subsidiaries (joint ventures are classified as an intermediate choice between these two extremes). Specifically, licensing gives weaker control over the strategic decisions concerning the foreign operation, it requires fewer dedicated assets, and it implies a much larger risk that firm-specific advantages in know-how will be disseminated. This approach suggests that strategic variables, environmental variables and transaction-specific variables can play a role in shaping the decision between licensing and wholly owned subsidiary.

\section{HYPOTHESES}

\section{Cultural Distance}

Globalized firms need to know how to run businesses in the host country to exploit their technological advantages and competencies at full effect. The greater the distance in values, customs and behaviors between their home country and the host country, the more difficult it is for foreign investors to operate successfully in the host country (Hofstede, 1980; Hennart and Larimo, 1998). Indeed, the routines and administrative structures that firms develop to manage domestic market operations are unlikely to be very sensitive to the signals flowing from culturally different business environments (Johanson and Vahlne, 1977).

However, the importance of cultural distance changes according to the way international businesses are organized (Hofstede, 1991). A wholly owned subsidiary requires the coordination of the foreign affiliate through expatriate managers, who have to live and work following the foreign customs. Instead a licensing contract is much less demanding in terms of acculturation. For example, the firm need not learn how to deal with suppliers or potential customers. The local licensee already possesses this knowledge. Indeed, the U-model explicitly postulates a positive relationship between the knowledge of the rules, norms and values of the foreign market and the level of resource commitment (Johanson and Vahlne, 1977). These observations lead to the following hypothesis:

H1: Cultural distance reduces the propensity of a firm to set up a wholly owned subsidiary rather than using licensing to exploit technological competencies in a foreign country.

The importance of cultural distance has been tested in several studies. Kogut and Singh (1988) found that greater cultural distance increased the probability that greenfield joint ventures would be preferred to wholly owned greenfields and to controlling acquisitions. Barkema, Bell and Pennings (1996) showed that the longevity of foreign ventures was negatively related to cultural distance. Hennart and Larimo (1998), in their comparative study of Japanese and Finnish investment in the US, found that greater cultural distance made more likely entry through shared-equity ventures. However, Contractor and Kundu (1998), using data on the worldwide hotel industry, found no effect of cultural distance, and Kim and Daniels (1991) reported similar results.

\section{Learning Through Past Experience}

Although we focus on the decision concerning a single production site, the process of penetration in a foreign country is by its nature a dynamic process (Johanson and Vahlne, 1977). Firms that 
expand abroad are likely to acquire knowledge about foreign sites, including foreign culture, institutional characteristics, and other site-specific knowledge. This experiential learning does not reduce the cultural distance between home and host country but certainly enhances the firm's experience in operating a business in a given foreign market (Root, 1987). A study by Eriksson et al. (1997) reported a strong negative relationship between both business and institutional knowledge and the perceived cost of internationalization. In other words, experiential learning endows the firm with greater ability to detect the opportunities, reduces the uncertainties of going abroad and makes the international investor more willing to commit a larger amount of resources. Consequently, we can state the following hypothesis:

H2: Experience in a given country increases the propensity of a firm to set up a wholly owned subsidiary rather than using licensing to exploit technological competencies.

Contractor and Kundu (1998) found that equity-based modes were preferred by companies with considerable experience and existing geographic reach. Similarly, Davidson (1983), Franko (1989), Gatignon and Anderson (1988) observed an increasing propensity to select wholly owned subsidiaries as experiential knowledge increased. However, Benito and Gripsrud (1992) rejected the hypothesis that current levels of direct investment in culturally remote countries increased with previous levels of foreign direct investment. Davidson and McFetridge (1985) showed a decrease in the reliance on wholly owned subsidiaries as foreign experience increased.

Finally, it is plausible that the experiential learning accumulated through past projects in a country depends on the form of the project. Projects that involve a stronger linkage with the local environment such as the creation of a wholly owned subsidiary or a joint venture with a local partner give the firm a more diverse and richer experience than a licensing arrangement (Johanson and Vahlne, 1977). This suggests the following hypothesis:

H3: Firms accumulate more experiential learning from equity investments than from licensing contracts.

\section{Number of Technology Suppliers}

Several studies have investigated the relationship between market structure and multinational investments (Caves, 1996). One stylized fact seems to emerge: foreign direct investments are more widespread in less competitive markets. This is also confirmed by the finding that multinational investments are largely targeted to differentiated and segmented industries where competition is less intense (Grubaugh, 1987).

This leads to an important consideration: the entry mode strategy cannot be analyzed in isolation from what other potential competitors do or might do. However, little attention has been devoted to this point by scholars in the field of international business studies. A firm investing in a foreign country is concerned with the present value of the future flows of profits, which have to be larger than the entry costs. Future profits are related to potential entrants in the market (Porter, 1985). Rival firms (both local and international) might be attracted by the presence of profitable businesses and start entering the market. Obviously an entrant needs to have access to the technology in order to start the production. All else equal, the more 
sources of technology (i.e. potential licensors) there are, the easier is entry since technology can be simply bought in the market, and more intense the competition (Lieberman, 1987; Arora et al., 2000). In turn, this would make it more difficult to recoup the costs of opening up a subsidiary in the foreign market.

H4: The larger the number of potential licensors for the technology employed in a given foreign project, the lower the propensity of the investor to set up a wholly owned subsidiary rather than using licensing for that project.

Testing this hypothesis involves an important qualification. As Kogut and Zander (1993) have pointed out, marketbased transactions in technology are more likely to occur when technologies are more codified and easier to transfer across organizational boundaries. Teece (1977) and Balakrishnan and Koza (1993) showed that the costs of transferring technology to other parties were lower in the case of more mature and standardized technologies, due to the reduced importance of asymmetric information and opportunistic behaviors. Arora and Gambardella (1994) and von Hippel (1994) also suggested that codification and standardization of knowledge makes technology transfer easier by reducing the difficulties of task-partitioning. This means that the number of potential licensors might simply be a proxy of more fundamental attributes of the technology. Accordingly, in our empirical analysis below, we control for characteristics of the technology such as complexity and codifiability to sort out these confounding effects.

\section{Methodology}

The unit of analysis of this study is an individual project (a chemical plant) un- dertaken in a foreign market. Our data on chemical projects undertaken abroad come from the Chemical Age Project File (CAPF), which covers all new chemical plants (over 20000) announced all over the world during the 1981-1991 period. The database provides the name of the company that operated the plant (or the names of the partners if the project was run under a joint venture) and that of the firm that licensed the technology. This allows us to identify whether, for a given project, the firm that ultimately possessed the technological capability, chose to set up a wholly owned operation or to adopt a licensing strategy. In addition, the database reports for each plant the type of process technology that was used for production. For instance, it is possible to identify all plants that produced "ammonia" distinguishing them from those that produced "acetic acid". To clarify terminology, in the reminder of the paper, we shall treat all "ammonia" (or "acetic acid") plants as belonging to the same technology sub-class, which we shall refer to simply as 'technology'.

In our empirical analysis we focus on a sample of large chemical firms. These firms are all chemical firms from developed countries that had more than $\$ 1$ billion of total turnover by the year 1988 and at least one investment project during the 1981-1991 period in our database. This yields a set of 153 chemical firms, of which 68 are North American, 32 Japanese and 53 West European. We restricted our attention to this sample of large firms because we had to collect firm-specific variables that our database did not provide. These firms accounted for overseas investment of about $\$ 50$ billion a year during the period under study and close to $50 \%$ of all overseas investment in the chemical industry. ${ }^{1}$ Specifi- 
cally, in the time period, they granted 1696 international licenses and undertook 2638 wholly owned foreign projects.

In the econometric analysis below, we exploit the time dimension of the data and split the investment projects in two periods: 1981-1985 and 1986-1991. In our sample, there are 1154 wholly owned projects and 737 licenses in the first period and respectively 1484 and 959 in the second period. We run our regressions only on projects undertaken in the second period and use the first period observations to construct some of the independent variables (see below). This allows us to control better for other factors that affect the choice between wholly owned subsidiary and licensing, avoiding potential endogeneity problems. In some of our model specifications, with the purpose of controlling for the nature of technology, we restrict our set of projects undertaken abroad to the ones belonging to a sample of 136 technologies. These are the most important technologies in chemicals and cover about $75 \%$ of all projects undertaken abroad.

\section{Variables}

Mode of entry. A wholly owned project is a plant abroad for which the database identifies any of the firms of our sample as the exclusive owner. Licensing is a plant abroad for which the database reports any of the firms of our sample as licensor of the technology, but not as owner of the plant. We capture this dichotomy in the entry mode through a binomial dependent variable that takes the value of 1 in case of wholly owned project and the value of 0 in case of licensing.

Cultural distance. (CULTDIST) We measure the cultural distance between the home and the host country using the four cultural dimension classification developed by Hofstede (1980, 1991). For a given country-pair, the cultural distance is calculated as the arithmetic average of the deviations in Hofstede's four dimensions, correcting for the overall variance of each of these four dimensions (Kogut and Singh, 1988).

Experience. We use two separate measures of experience to capture differences in the experiential learning accumulated through the different investment modes chosen for the foreign projects. EXPALL measures experience as the total number of projects (of all types) in a given country in the five years preceding the project under study. EXPEQUITY includes only projects which involved some forms of equity investment in the foreign country, either wholly owned projects or projects operated jointly with local firms. Using different time spans for measuring experience yielded similar qualitative results.

Potential licensors. (POTLIC) We want to capture the presence of other sources of technological competencies. In other words, we would like to know how many other firms were capable of supplying the technology that was used in a given plant. We do so by counting the number of firms (excluding the investing firm) that licensed a given technology in the period 1981-1985. This is a good proxy for the number of potential licensors of that technology in the period 1986-1991. An underlying assumption is that technological competencies are similar within a given technology and different across technologies.

\section{Control Variables}

Geographic distance. (PROXIMITY) This variable takes the value of 1 when the project undertaken abroad is in a 
country that shares borders with the home country or is located within a 100 mile range. It takes the value of 0 otherwise. Geographic closeness implies reduced communication costs. Geographic distance is generally related to psychic distance (Johanson and Vahlne, 1977), but they need not coincide. We include this variable to check whether cultural distance has any effect on the entry mode choice in addition to what is accounted for by geographic distance.

Language. (LANGUAGE) This dummy takes the value of 1 if the home and the host country have at least one of their official languages in common and 0 otherwise. Having the same language might imply reduced communication costs between foreign operations and headquarters. It might also imply an easier adaptation process for the expatriates who are sent abroad. Davidson (1983) reported that U.S.-based firms preferred to enter English-speaking countries first.

Firm size. (SIZE) We control for firm size because investments abroad require large financial and managerial resources, and expertise to venture into foreign markets. Small firms might lack these resources (Erramilli and Rao, 1993; Gomes-Casseres, 1989), and this suggests a negative relationship between firm size and licensing. However, Shane (1996) argued that the problems of human resource selection and management might grow even faster than the firm's growth in size, especially in international operations.

Degree of multinationality. (MULTI) This variable reports the number of countries in which the firm had directly invested in the period 1981-1985. This might capture firm experience in dealing with international investments. We expect that the degree of multinationality has a positive effect on the probability that the project undertaken abroad is carried out through a wholly owned operation (Johanson and Valhne, 1977; Erramilli and Rao, 1993).

Market size. (GDP) The size of the foreign market can actually influence the profitability of the investment and therefore the mode of entry in the foreign country (Gomes-Casseres, 1989; Zejan, 1990). We use the Barro-Lee database (a widely used source of country level data) to obtain information about the level of GDP in the host countries. GDP has two conflicting effects on the choice between a wholly owned project and licensing. On the one hand, a small market may not be worth the effort, particularly since any learning is likely to have only limited applicability (Gomez-Casseres, 1990). On the other hand, a large market may also be more competitive, implying that licensing may be a more attractive strategy. Also, a larger market may offer a larger pool of suitable potential licensees, an important consideration for the licensing strategy, particularly in developing country markets (Contractor, 1981).

Tariffs on intermediate inputs and capital goods. (OWTI) The existence of restrictions to both capital investments and trade of inputs might reduce the profitability of a direct investment in the foreign country (Contractor, 1990; Gomes-Casseres, 1990). To capture this effect we use the level of tariffs on capital investments and intermediate inputs, from the Barro-Lee database.

Country risk. (NORISK) The more uncertain the returns from the project undertaken abroad, the less willing the firm is to commit resources (Kim and Hwang, 1992). This would suggest that countries characterized by a higher level of risk should attract relatively less wholly owned projects and more licensing. We 
use a measure of country risk developed by the International Country Risk Guide. For the interpretation of the sign, one should be aware that a higher value of this variable is associated with less risk in the country.

Codifiable technology. (CODIFIABILITY) Codification makes a technology more transparent and easier to value by a prospective buyer, thereby reducing the information asymmetry problem in technology transfer (Teece, 1977; Balakrishnan and Koza, 1993). Codification also makes the knowledge less sticky (von Hippel, 1994) and reduces the direct costs of information exchange across firm boundaries that a licensing agreement would entail (Kogut and Zander, 1993). We measure the degree of codifiability of the technology using the number of patents reported for a given technology at the US Patent Office over the 1976-1991 period. As several authors have noted (Teece, 1988; von Hippel, 1994; Arora and Gambardella, 1994), patents are more likely to be issued for technologies where the underlying knowledge is sufficiently codifiable. However, patent data are organized in patent classes that are typically much coarser than the level of our chemical technologies. Therefore, we developed a set of queries for collecting the number of patents on the 136 chemical technologies in our sample from the online US Patent Office database. ${ }^{2}$

Complex technology. (COMPLEXITY) We use the definition of complexity provided by Kogut and Zander (1993). Complexity is the number of critical and interacting elements embraced by an entity or activity. Hence, a typical "complex" technology will show a large number of different uses, product and end-use applications, multiple inputs and components. We identified such number through a careful process, supervised by a chemist, that involved reading the patent abstracts and constructing queries to search the US Patent Office online database. Complexity makes marketbased technology transactions more difficult (von Hippel, 1994; Kogut and Zander, 1993). Table 1 gives the operationalization of the explanatory variables and shows their predicted sign.

\section{RESULTS}

\section{A First Cut at the Data}

This section is intended to convince the reader that the results we obtain from our logit regressions are robust to the untestable restrictions that parametric analysis necessarily imposes on the data. We provide here three figures that support our main hypotheses. We define "propensity to internalize" (henceforth PI) as the ratio between the number of wholly owned projects and the sum of licensed and wholly owned projects. An increase in this ratio means that we observe more vertically integrated governance structures for the projects undertaken abroad. Notice that PI is not measured at the level of the firm, but at the level of the classes of the explanatory variables reported in each of the figures below.

Figure 1 shows how greater cultural distance between home and host country reduces the likelihood that a foreign project is carried out through a wholly owned operation rather than by licensing. We have constructed five classes that are intended to capture different levels of cultural distance. Classes broadly correspond to quintiles. Countries which are very similar in Hofstede's four dimensions, like United States and Australia or Germany and Austria, enter in the first class labeled "same culture". Coun- 


\section{TABLE 1}

\section{Explanatory Variables, Operationalization and Expected Sign}

\begin{tabular}{|c|c|c|}
\hline $\begin{array}{l}\text { Independent } \\
\text { Variable }\end{array}$ & Operationalization & $\begin{array}{c}\text { Expected } \\
\text { Sign }\end{array}$ \\
\hline CULTDIST & $\begin{array}{l}=\left(\dot{f}_{\text {home }}-P_{\text {host }}\right)^{2} / 4 V^{i} \text { where } \dot{P}, \mathrm{j}=1,2,3,4 \text { are four } \\
\text { cultural indexes from Hofstede }(1980) \text { and } V^{j} \text { is the } \\
\text { variance of the jth index. }\end{array}$ & - \\
\hline EXPALL & $\begin{array}{l}=\text { number of investment projects (all types) in a given } \\
\text { country in the } 5 \text { years preceding the project under study }\end{array}$ & + \\
\hline EXPEQUITY & $\begin{array}{l}=\text { number of equity investments in a given country in the } \\
5 \text { years preceding the project under study }\end{array}$ & + \\
\hline POTLIC & $\begin{array}{l}=\text { number of licensors (except the investor), 1981-85, in } \\
\text { the technology sub-class to which the foreign project } \\
\text { belonged }\end{array}$ & - \\
\hline PROXIMITY & $\begin{array}{l}=1 \text { when the project was undertaken in a country which } \\
\text { shares some common borders with the home country; } \\
=0 \text { otherwise }\end{array}$ & + \\
\hline LANGUAGE & $\begin{array}{l}=1 \text { when the home and the host country have at least } \\
\text { one of their official languages in common; } \\
=0 \text { otherwise }\end{array}$ & + \\
\hline GDP & $\begin{array}{l}=\text { gross domestic product of the country which hosted the } \\
\text { foreign project (Barro-Lee) }\end{array}$ & $+1-$ \\
\hline OWTI & $\begin{array}{l}=\text { level of tariffs on capital investments and intermediate } \\
\text { inputs of the country which hosted the foreign project } \\
\text { (Barro-Lee) }\end{array}$ & - \\
\hline NORISK & $\begin{array}{l}=\text { weighted measure of the political, economic and } \\
\text { financial risk of the country which hosted the foreign } \\
\text { project (International Country Risk Guide) }\end{array}$ & + \\
\hline SIZE & $=$ investor's total turnover by 1988 (Aftalion, 1989) & $+1-$ \\
\hline MULTI & $\begin{aligned} &= \text { number of countries in which the investor had directly } \\
& \text { invested in the period } 1981-85\end{aligned}$ & + \\
\hline CODIFIABILITY & $\begin{array}{l}=\text { number of patents reported in the U.S. Patent Office } \\
(1976-1991) \text { in the technology sub-class to which the } \\
\text { foreign project belonged. Standardized to take values } \\
\text { between } 0 \text { and } 1\end{array}$ & - \\
\hline COMPLEXITY & $\begin{array}{l}=\text { number of different uses, product and end-use } \\
\text { applications, multiple inputs and components of the } \\
\text { technology employed in the foreign project. } \\
\text { Standardized to take values between } 0 \text { and } 1\end{array}$ & + \\
\hline
\end{tabular}

tries which are very different in all four dimensions, like Japan and Morocco or Sweden and Japan, are in the "opposite culture" class. ${ }^{3}$

Figure 2 shows the effect of country experience on the decision between wholly owned project and technology licensing. We have divided the observations in three groups. The first group in- cludes all projects for which the firm had no experience in the country in the preceding five years. The second group contains all projects for which the investor had accumulated some 'general' country experience, be it from licensing, joint ventures, or wholly owned projects. The last group only considers the projects for which the firm had accumulated more 




'qualified' experiential learning through prior investments entailing greater involvement with the foreign country business environment such as joint ventures or wholly owned projects. The figure underscores that country-specific experience makes future investments through wholly owned projects rather than licensing more likely, and this effect is more pronounced when the experiential learning comes from prior projects en-

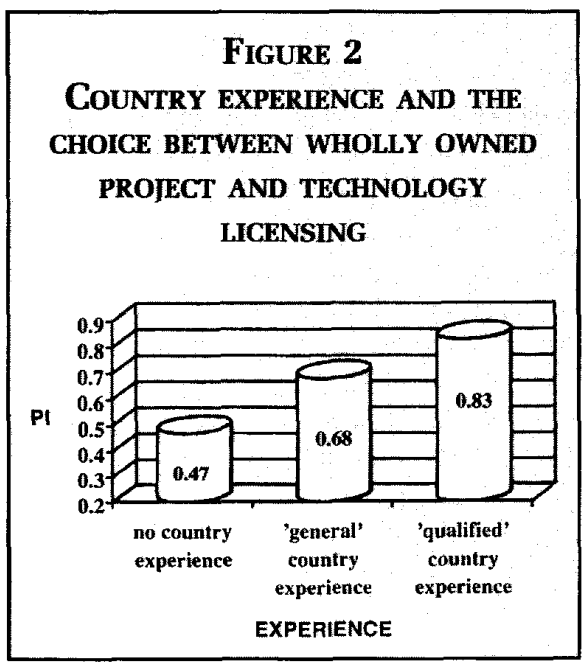

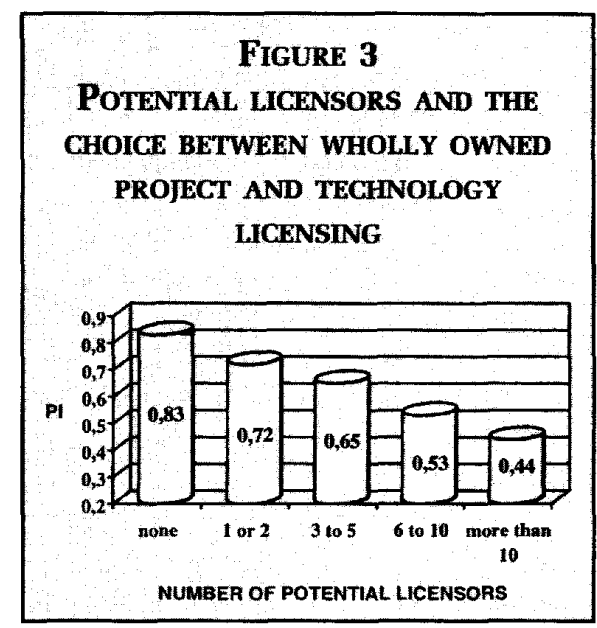

tailing greater involvement with the foreign country business environment.

Figure 3 shows the influence of the number of sources of technological competencies (i.e. the number of potential licensors) on the choice between wholly owned project and technology licensing. We have constructed five different classes ranging from no potential licensors to many. For instance, the last class includes all technologies for which we counted more than 10 potential licensors. Although the construction of the classes is somewhat arbitrary, experiments with different groupings show no significant changes in the results. As expected, the PI is the largest when there are no potential licensors. The PI decreases as we move to classes which include technologies with a larger number of potential licensors.

\section{Logit Analysis}

The results of the binomial logit regression are presented in Table 2. A positive coefficient means that the independent variable tends to increase the probability of a wholly owned project, whereas a negative coefficient implies 


\begin{tabular}{|c|c|c|c|c|}
\hline \multicolumn{5}{|c|}{$\begin{array}{c}\text { Table } 2 \\
\text { Logit Regressions: Wholly OWNed Project }(=1) \text { Versus Technology } \\
\text { Licensing }(=0)\end{array}$} \\
\hline Variables & Model 1 & Model 2 & Model 3 & Model 4 \\
\hline Constant & $\begin{array}{l}1.705^{* * *} \\
(0.122)\end{array}$ & $\begin{array}{l}1.492^{* * *} \\
(0.122)\end{array}$ & $\begin{array}{c}-1.719^{* * *} \\
(0.578)\end{array}$ & $\begin{array}{c}-1.719 * * * \\
(0.580)\end{array}$ \\
\hline CULTDIST & $\begin{array}{c}-0.372^{\star * *} \\
(0.042)\end{array}$ & $\begin{array}{c}-0.316^{* * *} \\
(0.042)\end{array}$ & $\begin{array}{l}-0.234^{* * *} \\
(0.060)\end{array}$ & $\begin{array}{c}-0.204^{* * *} \\
(0.060)\end{array}$ \\
\hline EXPALL & $\begin{array}{l}0.048^{\star * *} \\
(0.009)\end{array}$ & & $\begin{array}{l}0.035^{* * *} \\
(0.010)\end{array}$ & \\
\hline EXPEQUITY & & $\begin{array}{l}0.100^{* * *} \\
(0.013)\end{array}$ & & $\begin{array}{l}0.082^{* * *} \\
(0.015)\end{array}$ \\
\hline POTLIC & $\begin{array}{l}-0.075^{\star \star \star} \\
(0.007)\end{array}$ & $\begin{array}{l}-0.075^{* * *} \\
(0.007)\end{array}$ & $\begin{array}{c}-0.028^{\star \star \star *} \\
(0.011)\end{array}$ & $\begin{array}{l}-0.029^{\star \star *} \\
(0.011)\end{array}$ \\
\hline PROXIMITY & & & $\begin{array}{l}1.073^{* * *} \\
(0.213)\end{array}$ & $\begin{array}{l}1.036^{* * *} \\
(0.214)\end{array}$ \\
\hline LANGUAGE & & & $\begin{array}{r}0.375^{*} \\
(0.205)\end{array}$ & $\begin{array}{c}0.320 \\
(0.205)\end{array}$ \\
\hline GDP & & & $\begin{array}{c}-0.000^{* *} \\
(0.000)\end{array}$ & $\begin{array}{l}-0.000^{* * *} \\
(0.000)\end{array}$ \\
\hline OWTI & & & $\begin{array}{l}-0.764^{* * *} \\
(0.273)\end{array}$ & $\begin{array}{c}-0.689^{* *} \\
(0.272)\end{array}$ \\
\hline NORISK & & & $\begin{array}{l}0.027^{* * *} \\
(0.005)\end{array}$ & $\begin{array}{l}0.026^{* * *} \\
(0.005)\end{array}$ \\
\hline SIZE & & & $\begin{array}{c}-0.000 \\
(0.000)\end{array}$ & $\begin{array}{c}-0.000 \\
(0.000)\end{array}$ \\
\hline MULTI & & & $\begin{array}{c}0.007 \\
(0.017)\end{array}$ & $\begin{array}{c}-0.004 \\
(0.017)\end{array}$ \\
\hline CODIFIABILITY & & & $\begin{array}{l}-1.097^{* * *} \\
(0.419)\end{array}$ & $\begin{array}{l}-1.093^{\star * *} \\
(0.423)\end{array}$ \\
\hline COMPLEXITY & & & $\begin{array}{l}2.067^{* \star *} \\
(0.545)\end{array}$ & $\begin{array}{l}2.172^{* \star *} \\
(0.556)\end{array}$ \\
\hline Number of obs. & 2133 & 2133 & 1297 & 1297 \\
\hline Log Likelihood & -1194.32 & -1166.44 & -726.52 & -711.77 \\
\hline Chi-squared & $326.73(3)$ & $382.50(3)$ & $318.50(12)$ & $348.00(12)$ \\
\hline Correctly classified & $70.0 \%$ & $71.1 \%$ & $73.1 \%$ & $74.0 \%$ \\
\hline \multicolumn{5}{|c|}{$\begin{array}{l}\text { Notes: } \\
\text { 1. Numbers in parentheses are standard deviations. } \\
\text { 2. }{ }^{*} p<0.1,{ }^{* *} p<0.05,{ }^{* \star *} p<0.01 \text {. }\end{array}$} \\
\hline
\end{tabular}

the opposite. We have estimated four different model specifications. Models 1 and 2 only include the explanatory variables whose sign was predicted by the hypotheses we have worked out above. We have used all projects undertaken abroad by the firms of our sample during the period 1986-1991 in the sixty countries for which the measure of cultural distance was available. This amounts to a total of 2133 projects, of which two thirds are wholly owned operations. Models 1 and 2 differ in the definition of country experience adopted. In model 1 , 
TABle 3

Means, Standard Deviations, and Correlations Between Independent VARIABLES (OBSERVATIONS $=1297$ )

\begin{tabular}{|c|c|c|c|c|c|c|c|c|c|c|c|c|c|c|c|}
\hline Variable & Mean & S.D. & 1 & 2 & 3 & 4 & 5 & 6 & 7 & $\mathbf{8}$ & $\mathbf{g}$ & 10 & 11 & 12 & 13 \\
\hline 1. CULTDIST & 1.79 & 1.35 & 1.00 & & & & & & & & & & & & \\
\hline 2. EXPALL & 6.221 & 11.80 & -0.38 & 1.00 & & & & & & & & & & & \\
\hline 3. EXPEQUITY & 5.201 & 10.61 & -0.39 & 0.99 & 1.00 & & & & & & & & & & \\
\hline 4. POTLIC & 10.37 & 6.02 & 0.08 & -0.07 & -0.07 & 1.00 & & & & & & & & & \\
\hline 5. PROXIMITY & 0.17 & 0.38 & -0.23 & -0.06 & -0.04 & -0.01 & 1.00 & & & & & & & & \\
\hline 6. LANGUAGE & 0.25 & 0.43 & -0.54 & 0.36 & 0.37 & -0.06 & 0.24 & 1.00 & & & & & & & \\
\hline 7. GDP & 904 & 1290 & -0.31 & 0.62 & 0.60 & -0.08 & -0.18 & 0.15 & 1.00 & & & & & & \\
\hline 8. OWTI & 0.14 & 0.28 & 0.11 & -0.14 & -0.16 & 0.08 & -0.15 & 0.08 & -0.14 & 1.00 & & & & & \\
\hline 9. NORISK & 75.10 & 16.81 & -0.41 & 0.35 & 0.35 & -0.06 & 0.20 & 0.29 & 0.45 & -0.44 & 1.00 & & & & \\
\hline 10. SIZE & 8524 & 6903 & -0.13 & 0.20 & 0.20 & -0.00 & -0.04 & 0.03 & 0.07 & $\quad 0.04$ & -0.03 & 1.00 & & & \\
\hline 11. MULTI & 9.02 & 5.64 & -0.16 & 0.39 & 0.39 & -0.04 & -0.06 & 0.20 & 0.08 & -0.04 & 0.04 & 0.66 & 1.00 & & \\
\hline 12. CODIFIABILITY & 0.71 & 0.17 & -0.05 & 0.02 & 0.01 & 0.15 & 0.03 & -0.02 & 0.02 & -0.10 & 0.10 & -0.15 & -0.02 & 1.00 & \\
\hline 13. COMPLEXITY & 0.61 & 0.12 & 0.04 & -0.10 & $\rightarrow 0.11$ & 0.18 & 0.03 & -0.09 & 0.02 & 0.03 & 0.02 & -0.11 & -0.11 & 0.26 & 1.00 \\
\hline
\end{tabular}

EXPALL measures experience as the number of projects (of all types) in a given country in the five years preceding the project under consideration. In model 2, EXPEQUITY includes only equity investments. Models 3 and 4 still maintain the above mentioned difference in the measure of country experience, and add several control variables. In particular, the inclusion of variables such as CODIFIABILITY and COMPLEXITY allows us to control more carefully for the nature of the technology, an important determinant of the entry mode choice (Kogut and Zander, 1993). Moreover, our explanatory variable, POTLIC, might simply be a proxy for the degree of maturity and standardization of the technology. Indeed, it is likely that we observe more potential licensors in technologies where the underlying knowledge base is more codified, better understood, and hence easier to transfer across firms. Therefore, the use of controls for the nature of technology should allow us to isolate the true effect of POTLIC from spurious sources of variation. For this reason, we focused on a sub-set of 136 technologies, for which we were able to compute the variables CODIFIABILITY and COMPLEXITY. This reduces to 1297 the number of projects considered in models 3 and 4, of which $57 \%$ are wholly owned operations. Notice that a model including only our control variables would explain around $15 \%$ of the variability in the data. However, the purpose of including control variables is to separate what might be confounding effects on the true coefficients of the explanatory variables.

Hypothesis 1 predicts that greater cultural distance increases the preference for licensing agreements. The parameter estimate of the effect of cultural distance (CULTDIST) is negative and highly significant in all specifications $(p<0.01)$. This supports Hypothesis 1. Notice that in models 3 and 4 we have introduced the variables PROXIMITY and LANGUAGE, both showing the expected positive sign. As we discussed above these variables might be partially correlated with CULTDIST. Table 3 reports correlation coefficients of respectively -0.54 and -0.23 . Indeed, when these variables are included, the magnitude of the effect of CULTDIST shrinks, thereby confirm- 
ing that in part cultural distance can be proxied by geographic distance and common language. However, it is worth noting that CULTDIST still maintains a negative and significant effect over and above what is accounted for by geographic distance and common language. Further, to check the robustness of this finding, we have performed several experiments (not reported here), for instance excluding from our regressions all investment projects in Japan and US investment projects in Canada, that might have driven the result. The coefficient of CULTDIST reduces its magnitude, but keeps its negative and significant sign.

Hypothesis 2 predicts that firms learn from previous experience and this learning contributes to reduce the cost of a wholly owned project in a foreign country. Regardless of the measure of experiential learning used (EXPALL or EXPEQUITY), the coefficient of the variable is positive and highly significant $(\mathrm{p}<$ 0.01 ), which supports the prediction of Hypothesis 2. Further, the estimated coefficient of EXPEQUITY is larger than that of EXPALL, with the marginal effect calculated at the means of the regressors being twice as large $(0.02$ versus 0.008 in models 3 and 4 respectively). Put differently, doubling the average level of experience would increase the probability of observing a wholly owned project by 0.049 in the case of EXPALL and by 0.094 in the case of EXPEQUITY. In addition, models 2 and 4 fit the data better than do models 1 and 3 respectively. This supports Hypothesis 3.

Hypothesis 4 suggests that a larger number of potential licensors makes it more difficult to recover the cost of the investment since entry by competitors is more likely (there is no exclusivity in the technological competencies). In turn, this implies that when the number of potential licensors is large, a firm prefers to use technology licensing rather than setting up a wholly owned project. Consistent with Hypotheses 4, the coefficient of POTLIC is negative and highly significant $(p<0.01)$. We would like to emphasize that POTLIC remains negative (although of smaller magnitude) and significant also in models 3 and 4 where we have controlled for many of the different sources of heterogeneity in our data, and in particular for the nature of the technology. Our results support the idea that more tacit and complex technologies are more difficult to transfer through marketbased transactions. In addition, they also suggest that POTLIC is not merely a surrogate for the degree of standardization of the technology.

The signs of the other variables are reasonable. Economic, financial and political risks and barriers on capital investments and intermediate goods increase the probability of licensing. GDP has a small negative effect on the probability of observing a wholly owned project, indicating that the large market benefits of the value of learning do not fully balance the availability of suitable licensees and the increased toughness of competition. The total turnover of the firm (SIZE) does not have a significant effect, and neither does the international experience of the investor (MULTI).

Finally, we would like to underline that we have tested the robustness of these results by extending our analysis to joint ventures. Indeed, we have run both multinomial and ordered logit regressions (not reported here), including in the definition of the dependent variable a category for the foreign projects that were characterized by a joint ownership with local partners. Overall, the results were consistent with those in Table 3, with joint ven- 
tures appearing as an intermediate case between wholly owned projects and licensing.

\section{Conclusions}

This study offers some fresh evidence on a crucial strategic decision by firms involved in global competition: When is licensing preferred to a wholly owned subsidiary for exploiting technological competencies abroad? To address this question we used a new database that covers all chemical plants constructed or under construction worldwide during the 1981-1991 period. We developed a sample of the overseas investments and licenses of the largest 153 chemical firms in the world. Although confined to one industry, our data set is rich and comprehensive. In addition, we believe that the results from the chemical industry can provide insights into other scale and technology intensive industries. Another strength of our analysis comes from the large number of firms' nationality included in our sample. By focusing on an industry, we can better control for differences in technology characteristics, such as codifiability and complexity, which is much more difficult in cross-industry studies. Finally, another important contribution of this paper is the analysis of the role of competition among technology suppliers in conditioning the choice of the mode of entry.

We find that cultural distance is an important limitation to the commitment of resources. Firms prefer to exploit their technological competencies through licensing when the target country is culturally distant from the home country. Our results also support the idea that learning influences the choice of the mode of foreign opera- tion. We find that prior experience in the host country increases the odds that the project is carried out through a wholly owned operation rather than licensing. Further, this experience is more valuable when it comes from prior projects that entail a greater degree of involvement with the foreign business environment such as joint ventures or wholly owned subsidiaries.

Our results also shed light on another research question that has been little explored empirically. Although it is widely accepted that a firm's expansion strategy cannot be analyzed in isolation, empirical studies on entry modes have typically ignored this point. We find that the presence of other sources of technological competencies favor the use of licensing visà-vis wholly owned projects. This is consistent with the idea that when there are many sources of technological competencies, the lack of technology does not constitute a barrier to entry. Indeed, an entrant does not need necessarily to develop the technology in order to start production because it can acquire it from any of the potential licensors. In turn, this is likely to make competition in the product market more intense and favor the use of licensing as foreign entry mode, which is less demanding in terms of resources and commitment.

As a byproduct, this paper supports the finding in Kogut and Zander (1993), namely that the nature of technology plays a critical role in the choice of the internationalization strategy of the technology holder. Indeed, we find that codifiability of technology encourages licensing. By contrast, technologies that are more complex tend to be transferred through internal rather than marketbased transactions. 


\section{Notes}

1. This estimate is computed using the average cost of investment in a given chemical project, slightly more than $\$ 100$ million.

2. We selected all relevant patents using a keyword search with the process as keyword. From these, we selected and read the full abstracts of patents that exactly fit our criterion. The patent classes (and subclasses) into which these patents were classified were examined to ensure that the invention was in fact a technology invention. These sub-classes of the US patent classification system were used along with the process name as the basis for Boolean queries of the US patent database to generate the final set of patents, one set for each technology. (The details of the Boolean queries are available upon request.) The titles (and some abstracts selected at random) of the patents in the final sample for each technology were examined to ensure that the final sample did not contain irrelevant patents.

3. Notice that cultural distance should play a weaker role in chemicals (industrial products) vis-à-vis consumer product industries. This is true insofar the understanding of consumers' relationships is concerned. However, the costs of acculturation for expatriate managers, the costs of understanding business practices rooted in a different culture or the costs of networking with the local context are likely to be important for industrial product industries as well.

\section{REFERENCES}

Arora, A. \& Gambardella, A. 1994. The Changing Technology of Technological Change. Research Policy, 23: 523532.

, Fosfuri, A. \& Gambardella, A. 2000. Specialized Technology Suppliers, International Spillovers and
Investment: Evidence from the Chemical Industry. Journal of Development Economics, forthcoming.

Balakrishnan, S. \& Koza, S. 1993. Information asymmetry, adverse selection and joint ventures. Journal of ECOnomic Behavior and Organization, 20(1): 99-118.

Barkema, H.G., Bell, J.H. \& Pennings, J.M. 1996. Foreign entry, cultural barriers, and learning. Strategic Management Journal, 17: 151-166.

Benito, G.R. \& Gripsrud, G. 1992. The expansion of foreign direct investments: Discrete rational location choices or a cultural learning process? Journal of International Business Studies, 23: 461476.

Caves, R.E. 1996. Multinational Enterprise and Economic Analysis. Second Edition. Cambridge University Press. Cambridge. UK.

Contractor, F.J. 1981. International Technology Transfer. D C Heath and Company, Lexington.

1990. Ownership patterns of U.S. joint ventures abroad and the liberalization of foreign government regulations in the 1980s: Evidence from the benchmark surveys. Journal of International Business Studies, 21: 5573.

\& Kundu, S.K. 1998. Modal Choice in a World of Alliances: Analyzing Organizational Forms in the International Hotel Sector. Journal of International Business Studies, 29: 325-358.

Cyert, R.M. \& March, J.G. 1963. A Behavioral Theory of the Firm. Prentice-Hall. Englewood Cliffs, NJ.

Davidson, W.H. 1983. Market similarity and market selection: Implications of international marketing strategy. Journal of Business Research, 11: 439-456. 
\& McFetridge, D.G. 1985. Key characteristics in the choice of international technology transfer mode. Journal of International Business Studies, 16: 5-21.

Dunning, J.H. 1981. International production and the multinational enterprise. Allen and Unwing, London.

Eriksson, K., Johanson, J., Majkgärd, A. \& Sharma, D.D. 1997. Experiential knowledge and cost in the internationalization process. Journal of International Business Studies, 28(2): 337-360.

Erramilli, M.K. \& Rao, C.P. 1993. Service firms' entry-mode choice: A modified transaction-cost analysis approach. Journal of Marketing, 57: 19-38.

Franko, L.G. 1989. Use of minority 50-50 joint ventures by U.S. multinationals during the 1970s: The interaction of host country policies and corporate strategies. Journal of International Business Studies, 20(1): 19-40.

Gatignon, H. \& Anderson, E. 1988. The multinational corporation's degree of control over foreign subsidiaries: An empirical test of a transaction cost explanation. Journal of Law, Economics, and Organization, 4(2): 305-335.

Gomes-Casseres, B. 1989. Ownership structures of foreign subsidiaries. Journal of Economic Behavior and Organization, 11: 1-25.

1990. Firm ownership preferences and host government restrictions: An integrated approach. Journal of International Business Studies, 21: 1-21.

Grubaugh, S. 1987. Determinants of Direct Foreign Investment. Review of Economics and Statistics, 69: 149-151.

Hennart, J.F \& Larimo, J. 1998. The Impact of Culture on the Strategy of Multinational Enterprises: Does National Origin Affect Ownership Decisions?.
Journal of International Business Studies, 29: 515-538.

Hill, C.W., Hwang, L.P. \& Kim, W.C. 1990. An eclectic theory of the choice of international entry mode. Strategic Management Journal, 11: 117-128.

Hofstede, G. 1980. Culture's consequences. International differences in work-related values. Beverly Hills, CA: Sage.

1991. Cultures and organizations: Software of the mind. Berkshire, England: McGraw-Hill.

Hymer, S.H. 1960. The international operations of national firms: A study of direct foreign investment. $\mathrm{PhD}$ dissertation, Massachusetts Institute of Technology, Cambridge. MA.

Johanson, J. \& Vahlne, J.E. 1977. The internationalization process of the firm: A model of knowledge development and increasing foreign market commitments. Journal of International Business Studies, 8: 23-32.

Kim, W.C. \& Hwang, P. 1992. Global strategy and the multinational's entry mode choice. Journal of International Business Studies, 23: 29-53.

\& Daniels, J. 1991. Marketing channel decisions of foreign manufacturing subsidiaries. Management International Review, 31: 123-38.

Kogut, B. \& Singh, H. 1988. The effect of national culture on the choice of entry mode. Journal of International Business Studies, 19: 411-32.

\& Zander, U. 1993. Knowledge of the firm and the evolutionary theory of the multinational corporation. Journal of International Business Studies, 24: 625-645.

Lieberman, M. 1987. Patents, Learning by Doing, and Market Structure in the Chemical Processing Industries. International Journal of Industrial Organization, 5: 257-276. 
Porter, M. 1985. Competitive Advantage: Creating and Sustaining Superior Performance. Free Press. New York.

Root, F.R. 1987. Entry Strategies for International Markets. Lexington Books, Lexington, MA.

Shane, S.A. 1996. Hybrid organizational arrangements and their implications for firm growth and survival: A study of new franchisors. Academy of Management Journal, 39(1): 216-34.

Teece, D.J. 1977. Technology transfer by multinational firms: The resource cost of transferring technological knowhow. Economic Journal. June. 1988. Technological Change and the Nature of the Firm. In: Dosi, G. et al. (Eds.), Technological Change and Economic Theory, Francis Printer Publishers, London.

Von Hippel, E. 1994. 'Sticky Information' and the Locus of Problem Solving: Implications for Innovation. Management Science, 40(4): 429439.

Williamson, O.E. 1991. Comparative economic organization - The analysis of discrete structural alternatives. $A d$ ministrative Science Quarterly, 36(4): 269-296.

Zejan, M. 1990. New ventures or acquisitions: The choice of Swedish multinational enterprises. Journal of Industrial Economics, 38: 349-355. 